\title{
Ejércitos y estereotipos. De la Inglaterra del XVII al Israel actual
}

\section{Armies and Stereotypes. From the 17th Century England to the Current Israel}

\author{
Pablo Rey García. Universidad Pontificia de Salamanca \\ Pedro Rivas Nieto. Universidad Pontificia de Salamanca \\ Recibido: 19-XI-2008 - Aceptado: 21-III-2009 \\ Resumen:
}

En este artículo trataremos de la noción de estereotipo, aplicada a las guerras, los ejércitos, los combatientes, los pueblos. En muchas ocasiones, a lo largo de la historia, la gente ha caído, guerras han sido ganadas, buques hundidos; y todo, por mor de un estereotipo. Estereotipo que en buena parte tiene su raíz en el anterior conflicto, en otro navío hundido, en otra batalla ganada.

Palabras clave:

Ejércitos, estereotipos, guerra, política, conflicto, negociación.

Abstract:

In this paper we will treat about the notion of stereotype, applied to the wars, the armies, the soldiers, the people. Many times along the History, people has fallen down, wars have been gained, manowars have been sunked; and evreything only because a stereotype. Stereotype that in good part has his roots in the previous conflict, in another sunked ship, in another gained battle.

Key Words:

Armies, Stereotypes, War, Politics, Conflict, Negociation. 
Las guerras se hacen

con principios simples

e imperativos cortos.

(Raymond Cartier, 1996: 195)

\section{Introducción}

Según define la Real Academia Española, el estereotipo es una imagen o idea aceptada comúnmente por un grupo o sociedad con carácter inmutable (RAE, 2001). El carácter inmutable debe ser tomado en un sentido amplio, es decir, con una vigencia permanente a lo largo del tiempo, que no sea una aceptación pasajera. Aún así los estereotipos pueden ser transformados, mediante la insistencia o la recurrencia en una determinada postura, faceta, sutileza, o matiz. No es fácil, y generalmente no es una acción que entre en el ámbito de lo consciente, lo cual supone no pocos quebraderos de cabeza para todos aquellos profesionales inmiscuidos en el ámbito de la "imagen pública”, desde vendedores y publicistas hasta políticos y gente del mismo jaez. En multitud de ocasiones el estereotipo sufre una evolución, pues la insistencia, interesada o no, en una de sus partes puede acabar cambiando el sentido original.

Generalmente el estereotipo se asocia a una calidad negativa, aunque ello no es siempre cierto, de nuevo. Como ha estudiado Aparici (1993), el estereotipo conlleva por norma general la clara identificación de un grupo, y supone el que esa identificación se haga de un modo que los propios rasgos identitarios suponen un lastre negativo para el grupo. Un grado más en la conformación del estereotipo es que este rasgo identitario negativo sea adscrito a la categoría de innato: ningún miembro de este grupo puede, por tanto, abandonar su condición negativa. Ya por último, la teoría del estereotipo explica que se produce una inversión en la causalidad del rasgo identitario: es el rasgo negativo el que conforma el grupo, el que hace estar al grupo en una determinada condición social, y no al revés.

¿Hasta qué punto es cierto un estereotipo? Siempre debe darse por sentado que alguna razón subyace en el fondo de cada uno de los miles de estereotipos que envenenan nuestra mente. Pero afortunadamente somos capaces de cuestionarlos, y hacernos esta pregunta: ¿qué hay de verdad en ellos?Y aplicándolo al campo que nos ocupa, los ejércitos, cuestionarnos, por ejemplo: ¿fueron realmente los norteamericanos los héroes liberadores de Europa en la segunda guerra mundial? ¿Son hoy los nuevos señores feudales en una sociedad interrelacionada? ¿Cómo es posible que los hijos de los presos de Auschwitz tengan un comportamiento tan poco considerado en Gaza y Cisjordania? Cuestiones complejas, porque no sólo atañen a la verdad histórica, cuestión harto difícil de discernir con claridad, sino a asuntos de percepciones, que son personales 
y mutables. En la misma línea de meditación: ¿hasta qué punto es fiable la mera realidad, sin que se puedan abarcar las infinitas perspectivas de que dota un contexto? Es decir, quizás fijándose sólo en un aspecto -el histórico, el económico, el moral- sea capaz un observador de conformarse un juicio, como si fuere un bit de información, al respecto de diversas cuestiones: ¿̨ue buena para la economía la guerra del 1914? Sí. Ergo, la guerra del 14, desde un punto de vista económico, activó los resortes del gasto, y fue buena. ¿Fueron los norteamericanos capaces, con su ayuda decisoria, de expurgar el cáncer nazi de Europa en el 45 ? Sí. Ergo, su intervención fue buena.

Las preguntas sencillas ayudan a tomar posiciones y juicios morales sencillos. Sin embargo las mismas o semejantes cuestiones, formuladas desde otra perspectiva, más o menos elaborada, pero sin duda diferente, llevan a respuestas no sólo diametralmente diferentes, sino dudosas en su mismo posicionamiento. Sólo por poner un ejemplo, la estrategia del bombardeo del 13, 14 y 15 de febrero de 1945 sobre Dresde tiene muchas y muy variadas lecturas. Dresde era un nudo ferroviario importantísimo, especialmente después de la destrucción de las líneas de primer orden entre Leipzig y Berlín; su industria, más de 100 fábricas, estaba intacta, porque no había sido bombardeada más que desde agosto del 44; su Volksturm, la milicia urbana, no había sido desarticulada para nutrir a unidades de primera línea, y estaba operativa, aunque mal armada; el IV sector militar, al que pertenecía Dresde, tenía 20.000 soldados, y fue declarado fortaleza en 1943, no con el apelativo ilusorio con el que Hitler gustaba designar a casi cada población, sino bajo los designios y la batuta del mucho más capaz Heinz Guderian (2007). Para mantener esta región de Dresden-Riese la ciudad acantonó a la 404 división de la Wehrmacht, así como a unidades menores de las WaffenSS, la Armada, la fuerza aérea y auxiliares de tierra de esta última ${ }^{1}$. Los soviéticos, en la conferencia de Yalta (11 de febrero de 1945), habían pedido un esfuerzo a los aliados en campos como los bombardeos intensivos de los puntos clave de la retaguardia del frente oriental alemán, como Dresde, Chemnitz, Berlín y Leipzig, para facilitar el avance desde el este. Dos días después, con una supremacía aérea muy clara, los aliados cumplían sobradamente esta petición. Existen por tanto motivos mera y diáfanamente militares.

Hay quien incluso ha querido ver en esta acción un ataque "preventivo" contra... los rusos (!). La explicación aportada es hacerles llegar a los soviéticos el mensaje siguiente: "si desde Londres llegamos a Dresde, desde Berlín llegaremos a Moscú”. El estratega coyuntural dirá por tanto que fue un aviso a navegantes comunistas. Sin embargo el estratega a largo plazo, utilizando este mismo argumento tan hipotético, dirá que esa "política" contribuyó a la disuasión venidera, y reconducirá el argumento de bueno a malo, o viceversa.

El potencial de estos últimos no es desdeñable: la defensa aérea, encuadrada en la Fuerza Aérea bajo el mando de Göring, poseía los temibles 8.8, de doble uso antiaéreo y antitanque. 
Y sin embargo, Dresde fue una barbaridad sin nombre, reconocida por Churchill, en oposición al pragmatismo de Arthur Harris, a la sazón jefe de bombardeos la Fuerza Aérea, que usaba un razonamiento puramente militar como el que acabamos de exponer.

En el mismo sentido se puede argumentar con diferentes varas de medir sobre las bombas atómicas. Indudablemente, el dolor humano, sin paliativos, fue terrible en Hiroshima y Nagasaki. Desde un punto de vista humano, hoy se podría argüir que la estrategia del "salto de la rana”, de isla en isla, utilizando la guerra convencional, hubiera sido más misericorde (Pauwels, 2002). A pesar del casi seguro alto número de víctimas (japoneses que resisten a toda costa en el suelo patrio, reforzados con las tropas inmovilizadas en el imperio continental, frente a unos americanos técnicamente más potentes, volcados en Asia una vez solucionado el problema europeo), todas estas víctimas serían militares, no inocentes ciudadanos. Sin embargo este planteamiento, más moralmente correcto a priori, no se tuvo en cuenta en su día, no por la ceguera moral de los altos estrategas, sino por una cuestión de economía de tiempo. No de suprema maldad. Estados Unidos hubiera necesitado tiempo y esfuerzo para trasladar a las mejores divisiones del teatro europeo al asiático, amén de rearmarlas y volverlas a suplir de efectivos. Tras Okinawa, las líneas americanas estaban extendidas en demasía, especialmente para un ejército japonés todavía capaz de presentar resistencia coherente. Las bombas atómicas fueron una solución tajante, una prueba de fuerza ante la que el emperador debió ceder. En una guerra, en principio entre militares, la preocupación por el enemigo es loable e incluso necesaria para que exista una cierta humanidad, pero el silogismo se reduce en caso extremo a considerar más importante al último de "mis" soldados que al primero de "sus" civiles. Precisamente porque la guerra, más que entre soldados y soldados, o soldados y civiles, se produce entre "mis” y “sus”, en abstracto.

El equilibrio entre el componente moral y el pragmatismo militar (la necesidad de la victoria) es delicado de hallar, es bueno conseguir, pero -la tragedia reside aquí- no siempre es posible. Como máxima realización de la virtud moral se habla del paradigma de negociación del "gana-gana", donde los dos negociadores consiguen cosas beneficiosas como solución a un enfrentamiento. Este paradigma quizás sea válido en alguna ocasión, pero mucho nos tememos que sea una postura ilusoria si se aplica fuera de la "comunicación metafísica" o las "sinergias corporativas". En un conflicto real sólo cabe la consecución de la victoria o la asunción de la derrota. Como grado óptimo, la victoria caballerosa, y la derrota honrosa, pero nada más. No se puede repartir algo entre dos, y pretender que "ganen", porque repartir es simplemente el antónimo de ganar. Y si alguien opina al contrario, que vaya a Bosnia, que aún quedan cosas por solucionar, no odios ancestrales, sino asuntos pragmáticos, del día a día. El enclave de Brcko, por ejemplo. A ver cómo se reparte un territorio entre dos, para que todos ganen. A no ser que se considere "ganar" a aspectos metafísicos, 
como el sentir la felicidad de pasear por unos campos que eran míos, pero ya no lo son. En ese caso, este ciudadano habrá ganado. Pero debemos considerar que esta ganancia no es la preferida por los afectados. En cualquier caso, el "gana-gana" necesita de una cosa fundamental: la anuencia de las partes. Es posible que nosotros, civilizados occidentales, consideremos como ganancia la felicidad a través de la renuncia (suena a la tradición ascética y eremítica, de honda raíz cristiana), pero es posible que la otra parte no. ¿Cómo negociamos el "gana-gana" con un fundamentalista suicida? En este conflicto no hay ganancia que ofrecer a la otra parte, sino pérdida segura para las dos. Y la otra parte ya tiene asumida su pérdida.

El equilibrio moral se logra con una serie enorme de requisitos, entre contrincantes de semejantes valores, para los que la ganancia sea semejante... y cuando el equilibrio moral no cuestiona la capacidad de victoria. Cuando un buque de guerra recoge a los náufragos lo hace porque el enemigo valora la vida de su adversario, pero no como valor absoluto, pues si así lo hubiera hecho no la pondría en riesgo hundiendo su buque. Antes valora la vida propia. Cuando un submarino detiene un mercante para darle hundimiento ${ }^{2}$, lo hace con la seguridad de que va desarmado. En el momento en que se arman mercantes, los submarinos dejan de advertir a sus presas. Cuando se hace una pausa nocturna en el combate para que los soldados no se pierdan en el desierto; cuando Israel ofrece paz por territorios (un "gana-gana” a priori), lo que ofrece no es una pérdida propia, porque los territorios no son suyos, los conquistó previamente. Ello no es mejor ni peor, ni bueno ni malo; es que el equilibrio moral siempre va un paso por detrás del pragmatismo militar.

Es indudable que las ideas influyen, que detrás de un ejército no sólo está la doctrina sino la orientación ideológica que rige el empleo de la fuerza, un juego de intereses contrapuestos. A fin de cuentas el uso de la fuerza implica el riesgo de la vida, y aunque caben casos de patriotismo en los que la vida sea entregada gratuitamente por parte del soldado, a pie de cañón (tanto en el 2 de mayo de 1808 en el parque de Monteleón en Madrid, como en las diferentes operaciones de paz actuales), porque este soldado cree en el ideal, en la bondad o en la virtud; por regla general detrás de un ejército en combate está una directriz de carácter político y, por tanto, interesado. No buena ni mala a priori, dado que la política es el arte de la gestión de lo común en beneficio de la mayoría, pero sí hay una intención y un interés. Incluso en los momentos históricos en que una afrenta al honor era cuestión digna de ser solucionada por las armas, con riesgo de la vida, no se podría hablar de gratuidad, sino de que esa defensa del honor -ese patriotismo- es el interés en sí mismo.

2 El protocolo de Londres de 1930, cuyo artículo 22, referente a la guerra submarina, fue ratificado por Alemania en 1936, y obligaba a los sumergibles a actuar como barcos de superficie al respecto de las presas mercantes, para detenerlas e inspeccionarlas. Esto suponía un grave trastorno para los submarinos, que no poseían potencia artillera y eran presa fácil si el mercante era un corsario encubierto (Doenitz, 1963: 14). 
Actualmente en occidente, y especialmente en España, el honor y el patriotismo están de rebajas. Casi criminalizados ambos sentimientos, el ciudadano medio asiste a la quema de banderas, al ultraje de símbolos e instituciones mediante pintadas callejeras o declaraciones políticas, y todo ello se escuda en la libertad de expresión. Quizás sea bueno poder expresarse con semejante ímpetu, pero es cuando menos llamativo el giro que ha dado la percepción del honor nacional en menos de un siglo en España. Por supuesto que todo ello gira en torno a aspectos políticos (los emergentes nacionalismos periféricos) e históricos (la democracia surgida de una dictadura fuertemente españolista), pero contrasta con la sensibilidad exacerbada que se mostró por ejemplo, en la gestión de la crisis que llevó a la primera guerra con Marruecos (1859-60): todo empezó porque a las afueras de Ceuta unos lugareños marroquíes derribaron un mojón con el escudo de España, y mutilaron este último. Pero había, tras ello, un interés (Acaso Deltell, 2007: 34 y ss.).

Y la percepción de esta intención y este interés es lo que crea el estereotipo. No el interés en sí mismo, la pura intención, pues esta se alberga nada más que en la mente de los rectores políticos; no en el pragmatismo militar, que como vemos es el factor dominante en cualquier operación armada; nada de esto es lo que crea el estereotipo, sino la percepción. La percepción de una imagen muchas veces irreal es lo que convierte al héroe en villano, al preso en dominador.

El estereotipo es una imagen creada a través del tiempo, fijada en el inconsciente colectivo mediante la recurrencia en asimilaciones, generalmente favorecidas por los “hechos clave", esos momentos cumbre que a través de la historia son los más relevantes, los que recurrentemente son citados como los más importantes a pesar de que no lo sean. Su importancia viene dada por otros factores, como son la cercanía, la similitud, lo llamativo... Son lo que Stefan Zweig (2002) llamaba "momentos estelares" o "miniaturas históricas". Aunque muchas veces esos momentos estelares sean parte de la intrahistoria, como el propio Zweig narraba en su libro; eso no es óbice para que la importancia conferida los eleve a la categoría de mito. Y de ahí, al estereotipo, existe apenas un paso. ¿Por qué el estereotipo de los toros, el tablao flamenco y la siesta para los españoles? Apenas un siglo antes, el español era reconocido por su seriedad, su sobriedad y su fiel infantería. Pero llega Hemingway, narra una visión cuando menos particular de la guerra civil, versión que causa furor en Norteamérica y se mitifica. A partir de ese momento, la batalla del estereotipo está ganada para la siesta y los toros. ¿Por qué Brasil es samba, playas y fútbol? Los medios de comunicación actuales no dan esa imagen de Brasilª a pesar de la im-

Pablo Rey y Esther Gambi presentaron un estudio sobre la imagen de Brasil en la prensa "seria” española (El Mundo y El País) en el curso de verano de la Universidad de Salamanca "Redescubriendo Brasil” (1-4 julio de 2008) en el que se demuestra que la imagen actual del país sudamericano es la de una potencia económica en crecimiento, con mucho movimiento cultural y un importante papel internacional. Sí es muy importante el fútbol, pero no se hace mención relevante a las playas, el turismo, el carnaval o el sexo; en ese caso ¿ por qué perdura el estereotipo? 
portancia del deporte en este país. Debemos entender que el estereotipo no se cambia ni siquiera con campañas públicas, por mucho esfuerzo que se ponga. El estereotipo se nutre de eventos clave, de tiempo y de imaginario colectivo. O se dispone del control de esas tres variables, o no se podrá modificar el estereotipo. Veremos, a continuación, ciertos ejemplos de estereotipos aplicados al mundo militar.

\section{El estereotipo errado: esos "salvajes africanos"}

Durante mucho tiempo, mientras España tenía un mundo colonial americano a sus pies, la frontera sur fue nada más que una preocupación accesoria, refugio de la berbería y sus piratas, el lugar en el que los rescoldos del Islam habían apagado su calor tras la expulsión del suelo europeo. Un territorio ignoto al que no se le presta más atención que la necesaria para llegar, por la ruta del sur, a las Indias, haciendo navegación de cabotaje. Las plazas de soberanía españolas, heredadas de la pasajera unión hispano portuguesa, sólo comienzan a tener importancia estratégica a raíz del tratado de Utrecht, por el cual España pierde Gibraltar. Ceuta se convierte en su par de equilibrio, el puesto de control español del estrecho... que mira a Europa. A sus espaldas, el sultanato marroquí, al que no se le presta mayor atención. Y no sin razón, puesto que para el control efectivo del estrecho hace falta en ese momento artillería pesada, sólo a disposición de los ejércitos europeos.

Sólo cuando el avance de la artillería permita el desarrollo -y la compra y el uso- de piezas de campaña por parte de los "salvajes africanos" (Deltell, 2004: 33), en el contexto de las ayudas inglesas a los marroquíes ante la expansión francesa en Argelia, España decide salvaguardar Ceuta de ataques artilleros mediante la fortificación del Otero, altiplano sucesivo al istmo tras el que se encuentra la ciudad; esta pequeña meseta, según los tratados de 1844 con el rey de Marruecos, debía ser usada para pasto, exclusivamente. La contravención del acuerdo llevará a la posterior guerra de 1859-60, victoriosa para las armas españolas. No interesa en este punto del discurso el devenir ni el resultado de la guerra, que soslayaremos con esta breve mención, sino la manera en la que se enfocó el conflicto.

En primer lugar, el estereotipo del marroquí como "pueblo africano", que carece de honor y de dignidad, propició el casus belli; como decimos, el hecho de fortificar el Otero hace que la culpabilidad recaiga en parte hispana, y es un hecho mínimo el que cambia la orientación de la culpa, y justifica las hostilidades. Frente a la "necesidad científica" se opone la falta de modales y de honor marroquí. Luego vendrá un crescendo de ofensas y muertes, que acabará en una guerra total. 
Los militares españoles, por fortuna, no creyeron en el estereotipo de una guerra de misión, de una colonización por el bien del colonizado, que ofrecían la prensa española y el sector político al completo. Simplemente, hicieron bien su trabajo, con los medios adecuados, y las tácticas necesarias. Desde Prim a Beigbeder, existió en España una casta de militares preocupados por distanciarse de arquetipos populares de sabiduría y por conocer de primera mano a los futuros enemigos. Incluso en los momentos más amargos, en los que se pone en duda la valía de las armas -debido a la derrota, principalmente- como en el Barranco del Lobo en 1909 o en Anual en 1921, incluso en esos momentos se dan casos de voces críticas, militares que, con razones, se muestran contrarios al desarrollo de las operaciones, que proponen otros modos de conducción de las mismas, o que cumplen con su obligación más allá del deber, precisamente porque no creen en el estereotipo de un ejército marroquí de desharrapados.

Obviamente el estereotipo no nace de la nada. Marruecos utilizó en el cerco de Tetuán cañones capturados a Portugal cuatro siglos antes (!), su caballería no era capaz de desbloquear la formación en cuadro de la infantería española, una táctica que en los campos de batalla europeos del momento estaba siendo más que cuestionada, por la debilidad de esta formación frente al tiro artillero bien dirigido; el trato para con los prisioneros españoles distaba de ser galante, sino más bien expeditivo, con prontas decapitaciones; el asalto a la bayoneta era empleado casi con impunidad por los españoles, por carecer los infantes marroquíes de este utensilio. Todo ello refuerza la imagen, propagada en la península por políticos y demagogos, de los combatientes marroquíes como una sarta de salvajes sin civilizar, a lo sumo agricultores, y por ende musulmanes.

El militar español es capaz de darse cuenta de que esto no es del todo cierto, y que este comportamiento responde a carencias en algunos aspectos (en técnica y material militar, por ejemplo), pero no es una cuestión sencilla ni baladí, como se presenta a la sociedad española, resumiéndola en una especie de incapacidad congénita, inmersa Europa en la colonización africana precisamente por mor de ese mismo falaz argumento. Cuando los ejércitos europeos, y especialmente los españoles, desembarcan en África, se dan cuenta de que el agricultor es el más feroz combatiente, porque defiende lo suyo; de que el moro maneja la guerra de guerrillas mejor que sus propios inventores, y de que si bien no conocían la táctica adecuada, poco tiempo le faltó al moro para aprenderla. En la propia campaña de 1859-60 los Húsares de la Princesa fueron diezmados (mejor, casi aniquilados) en una emboscada muy bien planeada por parte de tropas de infantería mora, en la batalla de los Castillejos, el primero de enero de 1860. Animados por la victoria, los marroquíes son capaces de hacer retroceder, a pesar de su inferioridad técnica y táctica, a los entrenados voluntarios españoles. Sólo una carga mitad suicida y mitad heroica de la División de Reserva de Prim (y un 
providencial auxilio de Zabala al mando del Segundo Cuerpo por el flanco marroquí) logró que la victoria permaneciera en manos españolas (Galdós, 2004). La potencia de las armas españolas, la cadencia de fuego, la artillería o la capacidad de la Armada de alimentar al ejército móvil (Segundo, Tercer y Cuarto Cuerpo, amén de la División de Reserva) lograron decantar la victoria.

El hecho clave, alimentado por los poderes políticos y militares, y por la apetencia del pueblo, fue que los españoles siempre resultaron victoriosos en sus luchas con los marroquíes, a pesar de alguna derrota contingente (los Castillejos o Anual). Los españoles hicieron que el estereotipo pesara sobre el ejército marroquí en multitud de ocasiones, y las victorias en campaña hicieron que no se cuestionara el estereotipo. Incluso luego, en Anual, cuando el desastre fue mayúsculo, se achacó no a que el ejército moro fuera equiparable, sino a las deficiencias del planteamiento español en la campaña. Y cuando el peso de las armas españolas se impone de nuevo, en la década posterior, no se magnifica al moro, para así lograr indirectamente la glorificación del vencedor (una suerte de David que derrota a Goliat); se ve como algo lógico. O en cualquier caso, se hace notar la superioridad numérica abrumadora o el genio militar de Abd el Krim como los factores determinantes ${ }^{4} .$. lo que conduce a que en igualdad numérica y ausente la casual presencia de la genialidad, el dominio europeo sería completo. Sólo la revisión historiográfica paciente es capaz de efectuar una reformulación no estereotipada del ejército marroquí (Bellido, 2005). Actualmente, la Armada Real del país alauita ha finalizado con Francia la compra de un navío de última generación ${ }^{5}$. Quizás ésta sea la puntilla a un estereotipo de "salvajes africanos" que no hace justicia a las fuerzas armadas de nuestro vecino del sur.

\section{Dos estereotipos y un ejército: ¿liberadores de Europa o dominadores capitalistas?}

Los norteamericanos, su ejército y su imagen, son cautivos de las políticas sucesivamente intervencionistas o aislacionistas que priman en la dirección de su rol internacional. Los avatares de la historia mundial les han llevado a participar activamente en las mayores conflagraciones del último siglo. En algunas de ellas el papel de buenos y malos, de desencadenantes del conflicto o de portadores de la razón, la justicia y la bondad estaban más o menos claros; en otros no tanto. En gran medida dependen de la parte desde la que se les juzgue: en Europa el distanciamiento es mayor. En los propios Estados Unidos sí existe el estereotipo de que sus fuerzas están del lado de la justicia. Y es en los propios Estados Unidos donde se asume o se niega este estereotipo.

4 Informe Picasso, en Leguineche, Manuel (1996: 139).

5 Concretamente una fragata multipropósito tipo FREMM, fruto de la colaboración italo-francesa, de las más avanzadas de su tipo, como declaró el Director General de la DCNS en un comunicado de la propia compañía, el 18 de abril de 2008, cuando se daba la noticia de la venta (comunicado disponible en http://www.dcnsgroup.com/medias/popup.php?id=191). 
Cuando los Estados Unidos acuden a la Gran Guerra Europea, su papel es el de auxiliares menores de la potencia primigenia, Gran Bretaña. Su rol es decisivo en algunos momentos; sus méritos, grandes; su imagen es la del compromiso, pero no la del héroe (Strachan, 2004). En la Segunda Guerra Mundial, por contra, el imaginario colectivo los ve como el apoyo imprescindible, la potencia económica, el capital humano y la capacidad técnica indispensable, puesta al servicio de los aliados, la democracia y la justicia, contra el enemigo totalitario, dictatorial y por ende, malvado. A fin de cuentas, el régimen nazi es el causante del mayor crimen contra la humanidad llevado a cabo por las sociedades modernas, el exterminio planificado de seres humanos. Salvo retorcidas interpretaciones, y salvando los casos particulares, los roles de buenos y malos pueden adscribirse claramente y sin discusión en el caso que nos ocupa ${ }^{6}$. Las aberraciones militares aliadas, los crímenes de guerra de los soviéticos, o la culpabilización de un país al completo tras la Guerra Mundial fueron minimizados moralmente en aras de mantener la idea (el estereotipo) de la bondad frente a la maldad. Si hubo mala dirección en las campañas, quedó tapada por la victoria final; si se cometieron barbaridades contra civiles, eran menores que las del bando contrario o imprescindibles para el fin último; si un alemán era verdaderamente malvado, todos podían serlo por acción u omisión. El estereotipo del Bien frente al Mal fue capaz de borrar las repercusiones o juicios morales de casi cualquier acción no del todo correcta. Hasta muchos años después no comienza a haber en Estados Unidos bibliografía que cuestione la dirección de la guerra, o los intereses mercantiles de la misma. Y ni por asomo existe un movimiento de reacción (de excombatientes, intelectuales, comediantes o deportistas) que hagan frente a una política estatal, como fue el caso de Vietnam o de la Segunda Guerra del Golfo (2003). Y el cine sigue siendo pródigo a la hora de prestar modelos y revestir de héroes a los americanos (Pearl Harbor es uno de los más recientes ejemplos).

La propaganda fue importante en aquellos años (cómo olvidar el The Army needs you, y el dedo indicador del tío Sam), pero ni siquiera el cuasi todopoderoso Ministerio de Educación Popular y Propaganda ${ }^{7}$ nazi, con todos sus recursos y resortes, fue capaz de inculturar un estereotipo, el del Bien contra el Mal. El potentísimo departamento de prensa y propaganda alemán no logró hacer triunfar totalmente en los propios ciudadanos del Reich la idea de que la bondad estaba encarnada por el régimen nazi, y el partido, el go-

6 No por ello debemos dejar de hacer notar ciertas contradicciones en el planteamiento, dado que entre los "buenos" del momento figuran países con modelos antidemocráticos, como la Unión Soviética, o aliados advenedizos como la dictadura brasileña. No es válida, por tanto, la idea de la "lucha por la democracia", tal como es hoy entendido el concepto. Admitamos la contradicción, y que la alianza de los verdaderos demócratas con países que no cumplían con el estándar de completa bondad era meramente utilitaria, algo así como un mal menor.

7 Del alemán, Reichsministerium für Volksaufklärung und Propaganda, abreviadamente Propagandaministerium, Ministerio de Propaganda. Para su historia, cfr. Sywottek (1976: 23). 
bierno y el sistema siempre se enfrentaron a una oposición contestataria a la que había que reprimir. Obviamente, en un sistema dictatorial, la represión es mucho más cruel que en una democracia, lo que impidió ver manifestaciones al estilo norteamericano. La disensión era sorda aunque latente. Desde el Estado Mayor (Loringhoven, 2007) a los círculos académicos (Pelegrín, 2006), pasando por el soldado de infantería o el ciudadano de pie $^{8}$. Y es que el estereotipo no se impone, aunque pueda ser catalizado.

\section{Alemania: un estereotipo interesado}

Asistimos desde hace un tiempo a la reivindicación del Buen Alemán, que quizás sea el movimiento basculante correspondiente a la demonización de todo el pueblo alemán causada por los pecados execrables cometidos por el régimen nazi; ambas posturas son en gran medida injustas. De una manera completamente pasional, se presentan actitudes minoritarias -como la resistencia de la Weisse Rose, el círculo del profesor Hube, o los diversos atentados contra Hitler- como la justificación indisoluble de la bondad del pueblo alemán.

Y es que este último punto, los atentados, son especialmente escabrosos. La justificación del comportamiento de un grupo de oficiales de la Wehrmacht, que atentó contra la vida de Hitler en 1944, en el atentado más famoso, está prendida con alfileres. No decimos que la intención de acabar con la guerra y con Hitler no fuera buena en sí misma. Loable, incluso. Pero es que parte de los involucrados en la conjura eran responsables de crímenes contra la humanidad -aparte de otras buenas personas como el Pastor Dietrich Bonhöffer- (Shirer, 1993: 978), como es el caso de Arthur Nebe, proveniente de la RSHA, Oficina de Seguridad del Reich, y responsable del Einsatzgruppe B, en el sector central del frente soviético. Sobre sus espaldas recaen las muertes de 45.467 almas judías ajusticiadas por su mandato ${ }^{9}$. Nebe, al igual que Stauffenberg, Goerdeler, o los demás implicados, compartía un mismo ideal, un mismo patriotismo, y una misma solución para la coyuntura histórica de Alemania. Como ellos, participó activamente en el atentado del 20 de julio, y fue encarcelado y martirizado. Pero no se puede decir que en sí misma, la actitud y la persona de Nebe fuera buena, salvo haciendo una acrobacia intelectual y logrando eliminar de la historia a esa media centena de millar de asesinados. La conjura del 24 de julio estuvo llena de casos semejantes, en los que la bondad del fin último ocultó a los ojos de la historia otro tipo de verdades: el general director del Ejército Interior, Friedrich Fromm, alma mater del atentado, no tuvo reparos en pasar por las armas a sus compa-

8 Aunque por mero pragmatismo, desconocimiento o aprovechamiento del río revuelto, gran parte de la población soportara o apoyara al régimen nazi (Goldhagen, 1998: 124).

9 Zentner, Christian (1998) Der Zweite Weltkrieg, Wilhelm Heyne Verlag, Múnich, p. 395. 
ñeros de conjura (entre ellos a los generales Beck y Olbricht, además de los coroneles Von Quirnheim y Von Stauffemberg) cuando vio que el plan podía no salir bien, como a la postre sucedió. Con ello pretendía mostrarse como inocente y leal a Hitler. El hecho de que funcionara o no este atentado, este plan, o la salvaguarda de la inocencia o la vida de Fromm son asuntos en cierto modo menores, a ojos morales. Lo mismo el hecho de que no funcionaron las conjuras de Von Treschkow y Von Schlabrendorff en 1943, o de Von der Busche el mismo año. Eso son síntomas de que exitió disensión, pero no pueden catalogar de buenos o malos, por el mero hecho de la existencia de esta disensión, al resto de sus connacionales.

La disensión fue algo relativamente habitual, especialmente en los círculos militares, desde el principio: la lista de generales destituidos por Hitler forma un rosario de considerables proporciones. Incluso los más fieles, las divisiones SS, contravinieron órdenes de una manera peligrosamente cotidiana (peligrosa para los intereses de Hitler, pero con base en decisiones ciertamente acertadas desde los parámetros militares). Y hubo equívocos: Langsdorf hundió el Graf Spee por miedo -hubiera podido batir a los cruceros ingleses que le esperaban- pero hay quien pretende ver en ello una acción humanitaria (Lacosta, 2006: 41). A veces la buena intención empaña los ojos del historiador, y pretendemos ver loables actitudes donde no hubo apenas nada. Y en función de esas loables actitudes, justificar moralmente a todo un conjunto.

Todos estos casos son interesantísimos para el historiador, para el politólogo, o para el aficionado a la ucronía. Pero no pueden convertirse en argumento para cimentar un nuevo estereotipo, pretendido, interesado. El que el pueblo alemán es bueno lo sabemos todos los que hayamos leído sin anteojeras, sabiendo que en la condición humana es en donde radica el germen del mal y la raíz del odio, no en la nacionalidad. Por eso, pretender llegar al mismo fin, la bondad un pueblo, a través de la justificación mediante ciertos actos coyunturales, no es más que un camino equivocado. Puede salir bien -caso de la Weisse Rose, la pureza contra la maldad-o puede ser errado, caso de la conjura del 20 de julio. El pueblo alemán es tan bueno y tan malo como el pueblo malayo, el turolense o el judío. Fueron malos y perniciosos, pecaminosos y malditos, una persona y un grupo, un momento histórico y una actitud, pero no un pueblo. Ni todos estaban al corriente del horror de los campos, ni todos lo ignoraban. Había de todo. Flaco favor hacen a esta idea los estereotipos interesados.

\section{El estereotipo justo: el poder naval británico}

En ocasiones el estereotipo nace de la historia acumulada, no sólo de un momento de gloria. La marina inglesa tiene fama bien ganada de ser la mayor y mejor preparada del mundo, fama que mantiene a pesar de que la célebre regla del 2:1 ya no se cumpla y haya quedado archivada en el baúl de las anécdotas. De hecho 
en la Gran Bretaña se produce el hecho de que la flota es identificada con la misma nación ${ }^{10}$. Desde el siglo XVII la corona británica intentó -y logró- mantener la proporción de su armada de tal modo que el total de sus naves fuera igual o superior a la suma de sus inmediatos competidores. Esta regla se cumplió frente a España y Francia a lo largo del XVIII, o contra Francia, Rusia, Italia, Alemania o los Estados Unidos a lo largo del siglo XIX y principios del XX ${ }^{11}$. Incluso en la Segunda Guerra Mundial se vivieron las consecuencias del tratado de Washington, por el que Alemania vería limitadas sus capacidades marítimas, en pro de la hegemonía británica. Suyas fueron las grandes victorias (Graf Spee, Bismark, Gaudo-Matapán) y los grandes reveses (Scapa Flow, Hood, Prince of Wales). La ayuda de 50 viejos destructores que los Estados Unidos cedieron a la Gran Bretaña fue el indicio de que algo estaba cambiando. Tras la guerra mundial la hegemonía pasó a las dos superpotencias resultantes, los Estados Unidos y la Unión Soviética. La supremacía marítima es actualmente dominio de la primera, con una apabullante presencia en todos los teatros marítimos.

Cuando el tonelaje mundial era de 6,8 millones de toneladas, en 1842, el de Inglaterra sola era de 2,8, 3,3 con sus colonias (De Brossard, 2003: 475). Tras ella, los Estados Unidos, con 2,18 y Francia, con 0,66. Sólo tras la Guerra Mundial se alteró el potencial: el tonelaje inglés se amplió de 1,3 -el mismo que los Estados Unidos, poco superior al 1,1 japonés- en 1939 a 2,5 millones de toneladas. Sin embargo, la capacidad industrial norteamericana hizo crecer a su marina hasta los 4,2 millones de toneladas ${ }^{12}$. Los diferentes planes navales americanos lograron alcanzar una supremacía que aún no han abandonado. Actualmente, la presencia de las flotas militares rusas, así como las australianas o japonesas no es menor y, sin embargo, los norteamericanos mantienen el control de los mares. Ni siquiera son concebibles operativos OTAN sin la presencia de unidades de la US Navy. Pero, y esto es lo sorprendente, el dominio norteamericano de los mares puede entenderse como coyuntural, fruto de la situación geopolítica, y especialmente de la capacidad tecnológica. En boca de todos están los famosos sistemas AEGIS o SPY, los cruceros Ticonderoga o Arleigh Burke. Obviamente estos condicionantes son los mismos que llevaron al predominio británico en su día, y no pretendemos restarle mérito a la US Navy. Pero la tradición marítima de la Gran Bretaña se mantiene viva en el imaginario colectivo, y es acompañada por una proyección estratégica acorde, en doctrina y unidades. Sin que los cambios en el panorama y la función de la flota y la doctrina desacompañen el paso (la pérdida del Imperio, la creación de la Common Wealth, el descargo de las funciones de gendarme mundial en los Es-

10 De hecho, el almirante De Brossard pone fecha a esta identificación, desde los años 1652-54 (De Brossard, 2003: 389).

11 Consultar sobre ello la extensa y exhaustiva obra en tres volúmenes de Rodger (2004), especialmente el tercer volumen, The Command of the Ocean, 1649-1815.

12 Las pérdidas durante la guerra fueron del siguiente orden: Gran Bretaña, 1,1 millones de toneladas; Estados Unidos, 0,5 millones de toneladas; Japón, 1’4 millones de toneladas (De Brossard, 2003: 639). 
tados Unidos y en la OTAN). El ejemplo de la Gran Bretaña en el espejo en el que debe mirarse España, con sus propias limitaciones y necesidades específicas. No se podrá llegar nunca al dominio de los mares absoluto mediante el despliegue tecnológico y de unidades, al modo de norteamérica, sino al adecuado crecimiento acorde a las necesidades de nuestra doctrina estratégica ${ }^{13}$. En estos casos el estereotipo es acertado y hace justicia.

\section{El ejército israelí: los estereotipos no negados}

Es fácil caer en el estereotipo, no del todo incorrecto, que habla de la capacidad del ejército Israelí como consecuencia del Holocausto: los desheredados de la tierra de pronto se encuentran con que tienen un pedazo de suelo y un fusil para defenderlo. Sin ser un pensamiento errado del todo, la capacidad de combate del pueblo judío es una tradición que se remonta a bastante antes del Holocausto. De hecho, con las Aliyot, las oleadas de inmigración, entre 1870 y 1914, y luego a lo largo de todo el siglo XX, la necesidad de protección comienza a hacerse patente. Las comunidades organizan elementos para la autodefensa, puesto que las autoridades -otomanas primero, británicas después- no están todo lo comprometidas con su protección como ellas quisieran.

La Bar-Giora, primera organización de guardas voluntarios fue fundada en 1907 en Neve-Tzedek, cerca de Jafa, tras el intento fallido de contratar árabes para las labores de seguridad. Dos años más tarde se organizaría la primera empresa de carácter nacional, los Hashomer, que estaban jerarquizados en tres grados: los veteranos de la Bar-Giora, los guardias Hashomer, y la reserva, concepto que ya no abandonará las instituciones armadas judías, y que estará formada por todos los obreros y granjeros judíos.

Una de las más modernas unidades, germen del actual ejército, fue el Cuerpo de Muleteros de Sión, de Jabotinsky, una suerte de cuerpo judío del Ejército Británico en la Palestina, destinado a minar el poderío turco en la Primera Guerra Mundial. La siguiente unidad histórica judía, heredera en cierto modo del espíritu anterior, es el 39 regimiento de fusileros del Rey, uno de los tres regimientos judíos establecidos en Egipto.

En 1940 muchos judíos palestinos, haciendo caso a su corazón, se alistan en el ejército británico. El año 1941 los verá combatir en Grecia, de la que se retirarán, para realizar tareas de guardia en los frentes de África del Norte. En ese momento hay tres batallones judíos y uno árabe, dentro del llamado Regimiento Palestino. La maniobra de disgregación es más publicitaria que otra cosa, pues el Muftí de Jerusalén está

13 Fundamentalmente, la de proyección estratégica. (Ministerio de Defensa, 2005: 117). 
haciendo propaganda entre los árabes para acercarlos al Eje. La opción, para los árabes, de unirse a los alemanes, significa la opción por la libertad, puesto que el dominador era el inglés. La creación del batallón palestino obedece, por tanto, a una maniobra de imagen pública, que dice a los árabes que la opción británica no es mala. Lo mismo acaeció en la comunidad judía, en la que tuvo lugar un fuerte debate que no acabó de manera concluyente. Ben-Gurión resumió la manera en que se zanjó la polémica: “Apoyaremos a los británicos en la guerra como si no existiese el Libro Blanco ${ }^{14}$, y combatiremos el Libro Blanco como si no hubiera guerra” (MFA). Esto era una declaración de principios que contenía dos opúsculos opuestos. Pero sirvió para salir del paso.

En julio de 1944 es aprobada una unidad enteramente judía, que será creada en septiembre de ese año, como una agrupación de infantería de tres batallones, con servicios anejos. En ella sirvieron, al principio, 5000 judíos, y aunque se denegó el combatir bajo bandera propia, el estandarte del regimiento era la enseña sionista.

Tras el periodo de formación la brigada entró en línea en el frente de Italia, en marzo del 45. Apenas le dio tiempo a combatir -aunque es memorable la batalla de Bir-el Harmat, en Libia- y fue acantonada en Tarvisio, Udine. Posteriormente sería estacionada en Béligica y Holanda, para ser disuelta en el verano de 1946. Sucintamente, esta es la historia de la Brigada Judía, que daría luego lugar a uno de los ejércitos más efectivos del mundo.

Las raíces de las armas israelíes son la revuelta árabe de 1936, cuando los judíos deciden que se deben dotar de organizaciones de autodefensa, ante la clara voluntad belicosa de sus compatriotas árabes, con los que compartían el yugo británico. Nacen así la Irgun Haganah, "Organización de Defensa”, más conocida por su segundo nombre, y la Irgún Zvai Leumi o IZL, al frente de la cual estaba el posteriormente Nobel de la Paz Menachem Begin, y que se caracterizaba por ser más violenta y agresiva que la anterior. De hecho, el IZL incluía a los británicos entre sus objetivos, en tanto que la Haganah logró mantener altas cotas de cooperación con ellos, especialmente durante la guerra: la Haganah, bajo la supervisión de Orde Wingate, oficial del ejército de Su Graciosa Majestad, tuvo la misión de proteger el oleoducto Irak-Haifa ${ }^{15}$. Tras la guerra, la actuación se volvió de nuevo contra los británicos, ambas organizaciones a una, lo que hace que Gran Bretaña mantenga una fuerza de 10.000 hombres en la zona (Westwood, 2003: 9). El precio de la cooperación entre Haganah y británicos fue una escisión aún más violenta de la IZL, el grupo Stern.

14 El Libro Blanco de 1939 o Libro de McDonald, por el ministro de Colonias que lo patrocinó, con sus restricciones a la emigración, contradecía los principios de la Declaración Balfour, ya ambiguos de por sí. El Libro está disponible en Lillian Goldman Law Library de la Yale Law School, en red en http://avalon.law.yale.edu/20th_century/brwh1939.asp.

15 El propio Moshe Dayan, al frente de su unidad de la Haganah, perdió el ojo cuando se enfrentaba a franceses de Vichy en Siria. 
En respuesta a esta proliferación de grupos terroristas los musulmanes organizaron la Najada y la Futuwa, que pueden ser considerados grupos paramilitares, más que terroristas. Estos grupos pretendían superar el localismo de las milicias de los sheiks, que se nutrían de civiles, pero no pasaron de ser milicias mal armadas. Junto a ellas, los grupos terroristas organizados en torno a la figura del Muftí de Jerusalén, uno dirigido por su primo Abd-el Kader el-Husseimi, y el otro por Hassan Salameh; sin importancia militar pero de carácter simbólico, también el grupúsculo de los Hermanos Musulmanes de Egipto. A su vez, en respuesta a estas iniciativas, los judíos pidieron y obtuvieron el permiso de los británicos para organizar su propia policía, el Palmach, cuyos 2.000 hombres estaban pagados por los británicos.

El Palmach recibió en sus filas a muchos veteranos de las guerras mundiales, así como a gran parte de los integrantes de la Haganah. Cuando se declaró la independencia, el 14 de mayo de 1948, y comenzó la primera guerra por la supervivencia del Estado de Israel, a estos hombres, unos 3.000, se les añadieron otros tantos procedentes del IZV y unos 1.000 del grupo Stern. El valor militar de estos dos últimos grupos era pobre, debido a la falta de disciplina, pero eran grandemente animosos. Por ende, la organización del Estado preveía la unión de 12.000 reclutas, además de la movilización a tiempo parcial de otros 30.000 soldados en caso de necesidad.

La razón de la efectividad del IDF se debe buscar, pues, en estas raíces históricas. Eran, en aquellos días, pocos, pero muy voluntariosos. El arma aérea estaba compuesta por 40 pilotos (20 de ellos procedentes de la RAF) y 11 aviones civiles. Los desertores británicos de origen judío eran numerosos, y su experiencia enriquecía indirectamente el ejército de Israel. Las dos primeras unidades acorazadas judías -con carros Cromwell-se erigieron gracias al saqueo de arsenales llevado a cabo por desertores. El enriquecimiento directo fue llevado a cabo por los asesores y colaboradores, judíos o pro-judíos, que auxiliaron al naciente ejército.

El milagro, que sí existió, fue la lucha contra el factor tiempo y contra el factor número. El primero queda retratado en la novela de Dominique Lapierre y Larry Collins, Oh, Jerusalén (Lapierre y Collins, 2007), pues es algo realmente novelístico cómo las autoridades judías lograron suplir en tan corto espacio de tiempo las carencias de armamento de un ejército: con los números arriba explicados, el Palmach tenía en su poder, en 1948, unos 1.000 fusiles y otras tantas ametralladoras, con muy poca munición. No destriparemos los métodos que explican los autores, gracias a los cuales se lograron introducir armas en Israel desde los lugares más inverosímiles del mundo, pues aún queda el otro factor, el número, para el que también está reservada la épica.

Los hechos decisivos que permitieron sobrevivir a los judíos en la guerra del 1948-49 fueron, además de la notable capacidad de reacción y resistencia mostradas, la descoordinación de las naciones árabes y la falta 
de capacidad combativa: los judíos no podían permitirse perder la guerra, los soldados árabes no querían lucharla. Es muy diferente luchar por la piel, defendiendo la casa, que luchar por un nebuloso ideal, atacando la casa ajena. Las razones militares son múltiples: las líneas internas estaban dominadas por los israelíes, la superioridad en personal, logística, armamento y organización se logró por parte de los judíos a partir de los primeros seis meses de guerra (Bar-On, 2006: 55). Los árabes, desde ese momento, adolecieron de munición y combustible. La dependencia árabe de Gran Bretaña en todos los órdenes hizo que el embargo de las Naciones Unidas les afectara en mayor medida que a los hebreos, que tenían contactos múltiples: en julio del 48, mes y medio después de la invasión, los israelíes habían logrado la igualdad en el campo del armamento pesado, en tanto que poco a poco lograrían la paridad en otros aspectos. Ése fue el verdadero milagro, a lucha contra el tiempo. Cualquier otro milagro, de carácter romántico o sentimental, por más bonito que sea, no es válido. Como explica Gelbert, los milagros, si acaso se producen, casi nunca lo hacen en la guerra (Gelber, 2006: 54). Oficialmente, Israel ha reconocido la superioridad de su ejército en la guerra del 1948-49, por boca de Ben Gurión incluso. El estereotipo de "los pocos contra los muchos", los herederos morales de Auschwitz y Treblinka o cosas semejantes, a pesar de ser enormemente populares, e incluso queridos por parte de quienes los usan, no dejan de ser estereotipos románticos. Hay razones militares, que si bien no invalidan lo que arriba apuntábamos (la defensa de la casa frente al ideal nebuloso), sí tienen mayor peso.

\section{A modo de conclusión}

En el caso del Ejército Israelí, no existió demasiado interés por negar un estereotipo, el de los hijos de Auschwitz alzados en armas, con la fuerza moral detrás, que les beneficiaba ante la imagen pública mundial. A pesar de que la postura oficial reconoció la superioridad israelí, el estereotipo fue dejado campar a sus anchas, sin ser el exacto reflejo de la realidad. En el caso de la Armada británica, el mismo estereotipo fue dejado sobrevivir; en primer lugar, porque era bondadoso para con el sujeto, y en segundo término, porque hacía justicia a la realidad, si no en la forma, sí en la esencia, del control de los mares mediante la proyección estratégica.

En los casos marroquí y norteamericano, se trata de dos estereotipos que no retrataron la realidad. En ningún caso el ejército marroquí era un atajo de harapientos desheredados, cual tribu salvaje, ni los estadounidenses eran tan "buenos" antes como "malos" ahora. En los tres casos existieron fuerzas interesadas en que se viera a estos sujetos como tales, por distintas razones, como se ha expuesto. Del mismo modo ocurre con Alemania, en un estereotipo que se hizo extensivo a toda la nación, en dos direcciones. El 
interés, entendido antes como moralidad justificante, y ahora como moda y reparación moral, no deben empañar la mirada, la persecución de la verdad, y la atribución de responsabilidades. O el reparto de parabienes.

Como es obvio, los estereotipos existen. Puede parecer una perogrullada, pero el hecho de que existan por sí mismos significa que no se puede pretender extirparlos, cual peste bubónica. Cierto es que no son generalmente bondadosos, pero deben ser tratados en función precisamente de su existencia: cuando una afirmación categórica lo sea en grado superlativo, pongámosla en cuarentena. Hágase sobre ella una crítica, compruébense sus extremos. Y quizás de ese modo nos alejemos del pensamiento fácil, de las deducciones sencillas. Porque a la guerra se llega, precisamente, por el principio simple, por el imperativo corto.

\section{Referencias bibliográficas}

Acaso Deltell, S. (2007): Una guerra olvidada. Marruecos, 1859-1860, Madrid: Inédita Editores.

Aparici, R., Coord. (1993): La Revolución de los medios audiovisuales. Madrid: Ediciones de la Torre.

Bar-On, M. (2006): Never Ending Conflict: Israeli Military History, Westport (CT-USA): Stackpole Books.

Bellido Andréu, A. (2005): El Alcántara en la retirada de Anual. La laureada debida. Madrid: Ministerio de Defensa.

Cartier, R. (1966): La Segunda Guerra Mundial, Planeta: Barcelona. DCNS. Disponible en Internet [URL] http:// www.dcnsgroup.com/medias/popup.php?id=191).

De Brossard, M. (2003): Historia Marítima del Mundo, Madrid: Edimat.

Doenitz, K. (1963): Diez años y veinte días. Barcelona: Luis de Caralt.

García Pelegrín, J. M. (2006): La Rosa Blanca, Barcelona: Libros Libres.

Gelber, Y. (2006): “The Israeli-Arab war of 1948: History versus Narratives”, en Bar-On, M., Never Ending Conflict: Israeli Military History, Westport (CT-USA): Stackpole Books.

Goldhagen, D. J. (1998): Los verdugos voluntarios de Hitler, Madrid: Taurus.

Guderian, H. (2007): Recuerdos de un soldado, Barcelona: Inédita Ediciones.

Lacosta, X. (2006): “Alemanes contra Hitler”, en Historia 16, núm. 358, febrero 2006 Leguineche, M. (1996): Annual 1921, el desastre de España en el Rif, Madrid: Alfaguara.

Libro Blanco de 1939 (British White Paper), disponible en http://avalon.law.yale.edu/20th_century/brwh1922.asp.

Loringhoven, B. F. von (2007): En el Búnker con Hitler, Madrid: Altaza. 
MFA, Ministerio de Defensa de Israel. Disponible en Internet [URL] http://www.mfa.gov.il.

Ministerio de Defensa (2005) Revisión Estratégica de la Defensa, Servicio de Publicaciones del Ministerio de Defensa. Disponible en Internet [URL] http://www.mde.es.

Pauwels, J. R. (2002): El mito de la guerra buena, Hondarribia: Hiru.

Pérez Galdós, B. (2004): Aita Tettauen, Madrid: Akal.

RAE, Real Academia de la Lengua Española (2001), Diccionario de la Lengua Española, 22 edición.

Rodger, N.A.M. (2004): A Naval History of Britain, The Command of the Ocean, 1649-1815, Nueva York: W.W. Northom \& Company.

Strachan, H. (2004): La Primera Guerra Mundial, Barcelona: Barcelona.

Shirer, W. L. (1993): Aufstieg und fall des Dritten Reiches, Colonia: Verlag Kiepenheuer \& Witsch.

Sywottek, J.(1976): Mobilmachung für den totalen Krieg. Die propagandistische Vorbereitung der deutschen Bevölkerung auf den Zweiten Weltkrieg. Múnich: Opladen.

Westwood, J. (2003): History of War in the Middle East, Londres: Grennwich Editions Zentner, C. (1998): Der Zweite Weltkrieg, Munich: Wilhelm Heyne Verlag.

Zweig, S. (2002): Momentos estelares de la Humanidad, Barcelona: Acantilado. 
